\title{
Antenatal Seropositivity to Toxoplasma, Rubella, Cytomegalovirus, Herpes Simplex Virus - 2 in Bad Obstetric History
}

\author{
Gowdara Rangaiah Jagannatha Babu ${ }^{1}$, Belgaum Vijayaraghavan Shamsundar ${ }^{2}$ \\ 1, 2 Department of Microbiology, Mysore Medical College and Research Institute, \\ Government Medical College, Mysuru, Karnataka, India.
}

\section{ABSTRACT}

\section{BACKGROUND}

We wanted to evaluate seropositivity of IgM specific antibodies to toxoplasma, rubella, cytomegalovirus and herpes simplex virus 2 in antenatal women with bad obstetric history (BOH).

\section{METHODS}

It was a prospective study with subjects in two groups, study and a control group. Antenatal women with bad obstetric history were considered as a study group in which 70 subjects were included and 20 cases of antenatal women without BOH were in the control group. After informed consent, detailed history was noted in the proforma and $5 \mathrm{ml}$ blood was collected aseptically in a vacutainer and serum was separated and subjected for demonstration of IgM antibody detection towards toxoplasma, rubella, cytomegalovirus and herpes simplex virus 2 was detected by ELISA using the commercial kit as per manufacturers' direction.

\section{RESULTS}

A total of 90 samples were tested. Study group of seventy (70) samples and control group of 20 from antenatal women. BOH history among the study group common was repeated abortion alone or in combination with others followed by intrauterine death alone or in combination. In the study group, IgM seropositivity was observed as follows with toxoplasma in 1(1.43\%), HSV2 in 4 (5.71 \%) and equivocal in $7.14 \%$. No antibody was detected towards rubella and CMV. The control group showed IgM seropositivity of $5 \%$ each for CMV and HSV-2 and equivocal results were noted in 10 $\%$ of cases for HSV-2. Seropositivity towards the pathogens was mainly observed in the younger age group of 21-25 years, HSV-2 seropositivity was observed in 18-20 years of age. The seropositivity to Toxoplasma was observed in the second trimester (13-24 weeks) and HSV-2 in the third trimester (25 to $36+$ weeks).

\section{CONCLUSIONS}

All antenatal women with BOH should be routinely screened for TORCH infections so that early diagnosis and appropriate intervention will help in the proper management of these cases.

\section{KEY WORDS}

TORCH Infections; Bad Obstetric History (BOH); IgM Specific ELISA
Corresponding Author:

Dr. Gowdara Rangaiah Jagannatha Babu, Assistant Professor,

Department of Microbiology, MMCRI, Mysuru,

Karnataka, India.

E-mail: sujanjbsuma@gmail.com

DOI: $10.14260 /$ jemds/2022/44

How to Cite This Article:

Babu GRJ, Shamsundar BV. Antenatal seropositivity to toxoplasma, rubella, cytomegalovirus, herpes simplex virus - 2 in bad obstetric history. J Evolution Med Dent Sci 2022;11(01):228-231, DOI: $10.14260 / \mathrm{jemds} / 2022 / 44$

Submission 20-12-2021,

Peer Review 22-01-2022,

Acceptance 29-01-2022,

Published 31-01-2022.

Copyright (C) 2022 Gowdara Rangaiah Jagannatha Babu et al. This is an open access article distributed under Creative Commons Attribution License [Attribution 4.0 International (CC BY 4.0)] 


\section{BACKGROUND}

Bad obstetric history (BOH) implies previous unfavourable foetal outcomes in terms of two or more consecutive spontaneous abortions, history of intrauterine foetal death (IUD), intrauterine growth retardation (IUGR), stillbirths, early neonatal death and/or congenital anomalies.1,2 Causes of bad obstetrics history (BOH) may be genetic, hormonal, abnormal maternal immune response and maternal infection. ${ }^{1}$

TORCH complex which includes toxoplasma, other infections, rubella virus, cytomegalovirus (CMV) and herpes simplex virus (HSV) is the major cause of $\mathrm{BOH}, 2,3$ which can cross the placenta and damage the developing foetus at various stages of gestation leading to pregnancy wastage. ${ }^{2}$

TORCH infections in the mother during the first 5 months of pregnancy lead to serious foetal complications which include miscarriage, congenital heart diseases, cataract or clouding of the eye, blindness and vision change, hearing impairment, microcephaly, mental retardation, anaemia, hepatosplenomegaly, pneumonia and stillbirths. ${ }^{4}$ TORCH infections can cause serious long term neurodevelopmental disabilities, such as birth defects, severe mental retardation or learning disorders which appear to be $5 \%$ to $10 \%$ or less. ${ }^{5,6}$ Some children appear normal at birth but develop behavioural, emotional or learning problems in later part of life. ${ }^{7}$

TORCH infections in women are usually asymptomatic and chronic. The social and reproductive maladjustment because of repeated pregnancy wastages, cost of treatment and morbidity caused to the infant make the TORCH group of infections a major cause of concern. The prevalence of these infections varies from one geographical area to another. ${ }^{2,8}$

Therefore, recognition of the maternal disease and foetal monitoring once the disease is recognised is important for all clinicians. Knowledge of these diseases will help the clinician to appropriately counsel the mothers on preventive measures to avoid these infections and the potential for adverse foetal outcomes when these infections are present. ${ }^{9}$ Hence, all antenatal women with $\mathrm{BOH}$ should be routinely screened for TORCH panel of tests as early diagnosis and appropriate intervention will help in the proper management of these cases. $^{1}$

The mother is the usual source of transmission of HSV to the foetus or newborn. Primary HSV infection during the first half of pregnancy is associated with increased frequency of spontaneous abortion, stillbirth, and congenital malformation ${ }^{10}$

The serodiagnosis of acute TORCH which includes Toxoplasma, Rubella, Cytomegalovirus, Herpes Simplex Virus 2 infections in pregnant women is usually established by the demonstration of seroconversion in paired sera or by demonstration of specific IgM antibodies. ${ }^{1}$ The presence of specific IgM antibodies suggests relatively recent infections. ${ }^{11,12}$ The present study was undertaken to know the prevalence of these infections in bad obstetrics history.

\section{METHODS}

This was a laboratory-based study conducted in a tertiary care hospital and the subjects were divided into two groups, antenatal women with bad obstetric history (BOH) in study group and antenatal women with no bad obstetric history in the control group from April 2021- December 2021

\section{Inclusion Criteria}

Inclusion criteria were antenatal women with a history of repeated abortions, IUD, IUGR, stillbirth, congenital anomalies and early neonatal death.

\section{Exclusion criteria}

It comprised the presence of other known factors that could lead to repeated pregnancy wastage which includes anatomic, endocrine, hormonal deficiencies, Rh incompatibility, diabetes mellitus, renal diseases and other infections such as syphilis, etc.

The study group included 70 consecutive cases and 20 cases of control. The sample size was estimated based on the prevalence of $\mathrm{BOH}$ cases with $5 \%$ for chance and $20 \%$ error. Cases and controls were chosen in the ratio of 4:1.

After selecting subjects, they were explained about the study in detail and written consent was obtained and history was recorded in the proforma prepared for the purpose.

From the subjects, about $5 \mathrm{ml}$ of venous blood was collected under strict aseptic precautions into vacutainers. Serum was separated and transferred to sterile screw-capped vials and stored at $4^{\circ} \mathrm{C}$ until it was further processed.

All serum samples were tested for the presence of specific IgM antibodies to toxoplasma, CMV, HSV-2 \& rubella by ELISA using commercial kits methodology and result interpretation were carried out as per manufacturer's instructions.

\section{Statistical Analysis}

Descriptive statistics were used. Chi-square test was used for significance. SPSS statistical package version 20 was used.

\section{RESULTS}

A total of 90 samples were tested. Study group of seventy (70) samples and control group of 20 from antenatal women were included. The study group subjects had repeated abortion and IUD as the common history. Repeated abortion alone or in combination with another foetal outcome like IUD, IUGR or stillbirth etc was observed in 50/70 i.e. (71\%). Intrauterine death alone or in a combination of other $\mathrm{BOH}$ was observed in $25 / 70(35.71 \%)$ of subjects. The details of distribution are shown in Table 1. 


\begin{tabular}{|c|c|c|}
\hline $\begin{array}{l}\text { Sl. } \\
\text { No. }\end{array}$ & Obstetric History & $\begin{array}{l}\text { Number } \\
\text { of Cases }\end{array}$ \\
\hline 1 & Repeated abortions & 16 \\
\hline 2 & Repeated abortion + IUD & 9 \\
\hline 3 & Repeated abortion + Still birth & 2 \\
\hline 4 & Repeated abortion + Early neonatal death & 6 \\
\hline 5 & Repeated abortion + Preterm delivery and stillborn & 3 \\
\hline 6 & Repeated abortion + Preterm delivery and early neonatal death & 2 \\
\hline 7 & Repeated abortion + IUD + Early neonatal death & 1 \\
\hline 8 & Repeated abortion + IUD + Preterm delivery with stillbirth & 1 \\
\hline 9 & $\begin{array}{c}\text { Repeated abortion + IUD + Preterm delivery with early neonatal } \\
\text { death }\end{array}$ & 1 \\
\hline 10 & Repeated abortion + Stillbirth + Early neonatal death & 3 \\
\hline 11 & Intrauterine death (IUD) & 6 \\
\hline 12 & IUD + Stillbirth & 1 \\
\hline 13 & IUD + Congenital anomaly & 1 \\
\hline 14 & IUD + Early neonatal death & 2 \\
\hline 15 & IUD + Preterm and early neonatal death & 1 \\
\hline 16 & IUD + Stillbirth + Early neonatal death & 1 \\
\hline 17 & IUD + Congenital anomaly + Early neonatal death & 1 \\
\hline 18 & IUGR + Early neonatal death & 1 \\
\hline 19 & Congenital anomaly & 3 \\
\hline 20 & Stillbirth + Congenital anomaly & 1 \\
\hline 21 & Early neonatal death & 3 \\
\hline 22 & Preterm delivery and Early neonatal death & 5 \\
\hline \multirow{2}{*}{\multicolumn{3}{|c|}{$\begin{array}{l}\text { Table 1. Distribution of } \mathrm{BOH} \text { among the Study Group } \\
\text { Tal }\end{array}$}} \\
\hline & & \\
\hline & a Uterine Death, IUGR=Intra Uterine Growth Retardatic & \\
\hline
\end{tabular}

\begin{tabular}{|ccc|}
\hline Sl. No. & Age Group (Years) & Study Group \\
1 & 18 to 20 & $10(14.3 \%)$ \\
2 & 21 to 25 & $34(48.6 \%)$ \\
3 & 26 to 30 & $25(35.7 \%)$ \\
4 & 31 to 35 & $1(1.42 \%)$ \\
5 & $>35$ & $0(0 \%)$ \\
& Total & $\mathbf{7 0}(\mathbf{1 0 0} \%)$ \\
\hline \multicolumn{2}{|c|}{ Table 2. Distribution of Study Subjects as Per the Age } \\
\hline
\end{tabular}

The majority of the subjects were in the age group of 2125 years followed by $26-30$ years

In the study group, IgM seropositivity was observed as follows towards toxoplasma in 1 (1.43 \%), HSV-2 in 4 (5.71\%) and equivocal in $7.14 \%$. No antibody was detected towards rubella and CMV.

The control group showed IgM seropositivity of $5 \%$ each for CMV and HSV-2 and equivocal results were noted in $10 \%$ of cases for HSV-2.

Seropositivity towards the pathogens was mainly observed in the younger age group of 21-25 years, HSV-2 seropositivity was observed in 18-20 years of age. The seropositivity to toxoplasma was observed in the second trimester (13-24 weeks) and HSV-2 in the third trimester (25 to 36 + weeks). If we look at the bad obstetrics history mainly repeated abortions and Intrauterine death. (Table 3)

\begin{tabular}{|ccc|}
\hline TESTS & Cases & Positive \\
& $\mathbf{N}=\mathbf{7 0}$ & Control \\
& $1(1.43)$ & $\mathbf{N}=\mathbf{2 0}$ \\
IgM Toxoplasma & $4(5.71)$ & $\mathrm{Nil}$ \\
IgM HSV & $\mathrm{Nil}$ & $1(5)$ \\
IgM CMV & 0.165 & $1(5)$ \\
P value & 0.165 \\
\hline Table 3. Distribution of Seropositivity in Study and Control Groups \\
\hline
\end{tabular}

\section{DISCUSSION}

In the present study, the IgM was demonstrated in the age group of 18-25 years which correlates well with the study carried out by Esraa Abdul Kareem Mohammad and Yahya Jirjees Salman. TORCH infections: positive toxoplasma IgM antibodies, CMV, Rubella and HHSV-2 were highly observed in sera of women ageing from 16 to 25 years, contributing the following rates $77.78 \% 50 \%, 75 \%$ and $48.58 \%$ for each respectively. $\mathrm{P}<0.05 .^{13}$

In the present study, it was observed that $1.43 \%$ were seropositive for IgM toxoplasma, which almost equals with the study of Jani RH and Dave M,14 i.e. 1.4\%. Other studies are in the range of $10.52 \%$ to $20 \%$. Dacosta J. et al. in $1991^{10}$ and Kishore J. et al. in $2003^{12}$ reported seropositivity of $2.9 \%$ and $4.3 \%$ respectively for toxoplasma IgM antibodies. There is a wide variation in the incidence of toxoplasmosis in different countries and its variable effects on pregnancy. 3,4

In a study conducted by Padmavathy M, Mangala Gowri, Malini J et al., the IgM antibody positivity to T. gondii, Rubella, CMV and HSV-2 was $5.8 \%, 4.6 \%, 9.2 \%$, and $2.3 \%$ respectively 15

Anti rubella IgM and anti-CMV IgM were not detected in our study. Other authors have reported seropositivity in the range of $4.66 \%$ to $28.6 \%$ and $4.2 \%$ to $26.7 \%$ for rubella and CMV IgM antibodies respectively.

The geographical distribution of TORCH infections varies from one place to other. ${ }^{2}$ Hence Rubella and CMV infections may not be prevalent in this part.

IgM HSV-2 antibody was detected in $5.71 \%(4 / 70)$. Turbadkar D, Mathur M, Rele M et al. in $2003^{1}$ reported $3.6 \%$ seropositivity for HSV-2 IgM antibody, which correlates with our study. Other studies for HSV IgM antibodies are in the range of $8.66 \%$ to $26.7 \%$.

The study conducted by Rajendra B Surpam, Usha P Kamlakar found the seropositivity for Toxoplasma gondii as $14.66 \%$, HSV $8.66 \%$, CMV 5.33 and rubella virus $4.66 \%$. While in the control cases the seropositivity for toxoplasma, rubella and CMV was $1.33 \%$ and for HSV $4 \%{ }^{2}$

A study conducted by Shrishti Makhijani and Sharmila S Raut showed that history of $\mathrm{BOH}$ cases consisted of spontaneous abortions in 80 cases (46.51\%), intrauterine deaths in 32 cases (18.60\%), early neonatal deaths in 24 cases (13.95\%), congenital malformations in 18 cases $(10.46 \%)$, stillbirths in 12 cases (06.97\%) and preterm labour in 6 cases $(03.48 \%)^{16}$ which are similar to our study.

All the four seropositive cases for HSV-2 were in the age group of less than 25 years and the third trimester of pregnancy.

In our study, IgM antibody to toxoplasma and rubella was not detected in the control group comprising of 20 cases of normal pregnant women. But $5 \%(1 / 20)$ seropositivity for IgM antibody to each of CMV and HSV-2 was detected in the control group who were asymptomatic.

\section{CONCLUSIONS}

The study showed the seropositivity towards toxoplasma in the second trimester which is a stage of organogenesis and herpes was seen in the third trimester. The transmission of primary infection with HSV2 usually spreads during parturition and the chances of the child developing the disease are very high considering the above scenario and it is better to screen for these infections in $\mathrm{BOH}$ cases.

The first visit to antenatal check-up itself is better to screen and follow up of these patients has to be done till delivery and utmost precaution to be taken for a good outcome. The limitation of the study is that the positive patients should have 
followed up till the delivery to know the outcome in the present pregnancy. The study needs to be done in a large population to have a great addition to the knowledge base.

Data sharing statement provided by the authors is available with the full text of this article at jemds.com.

Financial or other competing interests: None.

Disclosure forms provided by the authors are available with the full text of this article at jemds.com.

\section{REFERENCES}

[1] Turbadkar D, Mathur M, Rele M. Seroprevalence of TORCH infections in Bad Obstetric History. Indian J Med Microbiol 2003;21:108-10.

[2] Surpam RB, Kamalakar UP, Khadse RK, et al. Serological study for TORCH infections in women with bad obstetric history. J Obstet Gynecol India 2006;56(1):41-3.

[3] McCabe R, Remington JS. Toxoplasmosis: the time has come. N Engl J Med 1988;318(5):313-5.

[4] Martin E. TORCH Screen. Google Website 2001.

[5] Zhang CX, Mei Q, Zhu Y, et al. Protein microarray-a new tool for detection of TORCH infections; advanced nanomaterials and nanodevices. IUMRS-ICEM Jun 2002.

[6] Schendel DE. Infections in pregnancy and cerebral palsy. J Am Med Assoc 2001;56(3):105-8.

[7] Brochert A. TORCH Infections. Google Website 2001.

[8] Canessa A, Pantaratto F, Miletich F, et al. Antibody prevalence of torch agents in pregnant women and relative risk of congenital infections in Italy (Linguria). Biol Res Pregnancy Perinatal 1987;8(2 2D Half):84-8.

[9] Stegmann BJ, Carey JC. TORCH infections. Toxoplasmosis, other (syphilis, varicella-zoster, parvovirus B19), rubella, cytomegalovirus (CMV), and herpes infections. Curr Womens Health Rep 2002;2(4):253-8.

[10] Khayyam N, Moin K, Vyas L, et al. Seroprevalence of torch infection in patients attending a tertiary care hospital with bad obstetric history. Int J Med Sci Educ 2017;4(4):393-9.

[11] Dacosta J, Dacosta N, Mehta A, et al. Toxoplasma IgM titers in women with BOH. J Obstet Gynecol 1991;41(2):158-9.

[12] Kishore J, Agarwal J, Agarwal S. Seroanalysis of Chlamydia trachomatis and S-TORCH agents in women with recurrent spontaneous abortions. Indian J Pathol Microbiol 2003;46(4):684-7.

[13] Mohammad EAK, Salman YJ. Study of TORCH infections in women with Bad Obstetric History (BOH) in Kirkuk city. Int J Curr Microbiol App Sci 2014;3(10):700-9.

[14] Jani RH, Dave M. Toxoplasma infections: perspective. Journal of Int Med 1994;4:36-46.

[15] Padmavathy M, Gowri M, Malini J, et al. Seroprevalence of TORCH infections and adverse reproductive outcome in current pregnancy with bad obstetric history. J Clin Biomed Sci 2013;3(2):62-71.

[16] Makhijani S, Raut SS. Seroprevalence of TORCH infection and adverse reproductive outcome in women with bad obstretic history. Indian J Obstet Gynecol Res 2021;8(1):49-52. 